Small Sample Properties of Panel Time-series Estimators with I(1) Errors

Jerry Coakley, Ana-Maria Fuertes and Ron Smith 


\title{
Small sample properties of panel time-series estimators with I(1) errors
}

\author{
Jerry Coakley ${ }^{a, b *}$, Ana-Maria Fuertes ${ }^{c}$, Ron $\operatorname{Smith}^{a}$ \\ ${ }^{a}$ Department of Economics, Birkbeck College, University of London \\ ${ }^{b}$ Department of Accounting, Finance and Management, University of Essex \\ ${ }^{c}$ Department of Accounting and Finance, City University Business School
}

April 2001

\begin{abstract}
Monte Carlo simulations are used to explore the small sample properties of a mean group and two pooled panel estimators of a regression coefficient when the regressor is $I(1)$. We compare and contrast the effect of $I(0)$ and $I(1)$ errors and homogeneous and heterogeneous coefficients in a design based on two typical PPP panels. The results confirm that the asymptotic theory is relevant to practical applications. With $I(0)$ errors and homogeneous coefficients, the estimators are unbiased, dispersion depends on the signal-noise ratio and falls at rate $T \sqrt{N}$ as expected. With $I(1)$ errors and no cointegration, the estimators are unbiased and dispersion falls at rate $\sqrt{N}$. When heterogeneity with $I(0)$ errors is introduced, the dispersion of the pooled estimators falls at rate $\sqrt{N}$ but that of the mean group continues to fall at rate $T \sqrt{N}$. Finally, the pooled estimators are likely to lead to distorted inference both in the case of $I(1)$ errors and of $I(0)$ errors with heterogeneous coefficients. The mean group estimators, however, are generally correctly sized.
\end{abstract}

Keywords: Monte Carlo; response surface; spurious regression; PPP JEL Classification: C32; F31

*Corresponding author: Tel: +440207 631 6418. Fax: +440207631 6416. E-mail: jcoakley@econ.bbk.ac.uk. 


\section{Introduction}

Panel time-series, where both $T$, the number of time periods, and $N$, the number of groups, are large, play an increasing role in empirical research. They are particularly important in international macroeconomics, since long runs of data are often available for many countries. Such panels have been used to study growth and convergence, the Feldstein-Horioka puzzle and, most extensively, purchasing power parity (PPP). Baltagi and Kao (2000) provide a survey of methods for non-stationary panels of this sort. When both $T$ and $N$ are large, one can model heterogeneity by permitting coefficients to vary between groups which is not possible in small $T$ panels. Baltagi and Griffin (1997) and Boyd and Smith (2000) show that such heterogeneity in group-specific coefficients is important in practice. Such panels also offer the prospect of overcoming the spurious regression problem which is not possible with small $N$ panels or pure time series. Phillips and Moon $(1999,2000)$ and Kao (1999) show that in such panels one can obtain consistent estimates of an average long run parameter even when the variables do not cointegrate or, equivalently, when the error term as well as the variables are $I(1)$. The intuition is that the noise - the covariance between the $I(1)$ error and the $I(1)$ regressor - that produces the spurious regression problem is attenuated by averaging over independent groups.

This paper uses Monte Carlo simulations to investigate the small-sample properties of three panel estimators in a static linear regression model where the variables are $I(1)$; the errors are either $I(0)$ (cointegration case) or $I(1)$ (no cointegration case); and the coefficients are either homogeneous or heterogeneous. The Monte Carlo design is calibrated on two contrasting PPP panels: one is a $T>N$ monthly data panel while the other is a $N>T$ annual data panel. Accordingly the results cover many of the typical panel dimensions used in applied work. The paper can be seen as a complement to Taylor (2001) who explains how temporal aggregation and non-linearities, because of bands of inaction, may make errors appear $I(1)$ even when adjustment is quite rapid. We address the issue of whether one can estimate the long run effects of price differentials on exchange rates even if the errors are $I(1)$ for those or other reasons.

If one knew the data generating process (DGP), one would use the information in levels in the cointegration case and first differences otherwise.

In principle one could test whether the variables cointegrate using any of the tests for cointegration and unit roots in panels surveyed by Baltagi and 
Kao (2000). In practice, as they emphasise, there are severe conceptual difficulties in formulating the appropriate hypotheses and the results are often inconclusive. In this light, one can view our simulations as answering the following question. What are the consequences of applying the various estimators to the data in levels when one is not sure whether some or all of the group-specific relations cointegrate?

Section 2 outlines the Monte Carlo design and reviews the estimators examined. Section 3 considers the properties of three static panel regression estimators under $I(0)$ and $I(1)$ errors when the regression coefficient is homogeneous across groups. We use response surface regressions to analyse the effect of innovation variances and panel dimensions. Section 4 investigates the case of heterogeneous slope coefficients. The PPP application is discussed further in Section 5 and a final section concludes.

\section{Monte Carlo design and estimators}

A simple Monte Carlo design is employed to compare the effect of $I(0)$ and $I(1)$ error terms. Data are generated on a dependent variable $y_{i t}$ and an exogenous regressor $x_{i t}$ for groups $i=1,2, \ldots, N$ and time periods $t=1,2, \ldots, T$, according to:

$$
\begin{gathered}
x_{i t}=x_{i, t-1}+\varepsilon_{x, i t}, \quad \varepsilon_{x, i t} \sim \operatorname{IN}\left(0, \sigma_{x, i}^{2}\right) \\
u_{i t}=\rho u_{i, t-1}+\varepsilon_{u, i t}, \quad \varepsilon_{u, i t} \sim I N\left(0, \sigma_{u, i}^{2}\right) \\
y_{i t}=\beta_{i} x_{i t}+u_{i t},
\end{gathered}
$$

where the disturbances $\varepsilon_{x, i t}$ and $\varepsilon_{u, i t}$ are also independent of each other. In this design, $x_{i t}$ is strictly exogenous; the data have no deterministic trends, the random walk for $x_{i t}$ has no drift; there are homogenous, zero, intercepts across groups; finally contemporaneous dependence between groups is excluded. ${ }^{1}$ In the first set of simulations we assume homogeneous slope coefficients $\beta_{i}=\beta=1$. In the second set we allow $\beta_{i}$ to vary over groups. We

\footnotetext{
${ }^{1}$ See Coakley and Fuertes (2000), Coakley, Fuertes and Smith (2001), Higgins and Zakrajšek (1999), O'Connell (1998) and Pedroni (1997) for discussions of cross sectional dependence.
} 
consider both the cointegration case with $\rho=0$ and no cointegration case with $\rho=1$. Since most of the properties of the estimators in the former case are well known, the Monte Carlo results provide a yardstick for comparison with the latter case.

The simulations are calibrated to match the panel dimensions and the innovation volatilities of two contrasting PPP datasets. In the first $N>T$ panel the signal-noise ratio (the innovation variance of the regressor relative to that of the disturbance) is large while in the second $T>N$ panel it is small. Panel I is based on the Boyd and Smith (1999) large $N$, small $T$, annual LDC dataset for (log) spot exchange rates and price differentials with the following characteristics:

$N=30, T=25, \sigma_{x, i} \sim U[0.25 \mp 0.15], \sigma_{u, i}=0.14 \forall i^{2}$

Panel II is based on the Coakley and Fuertes (2001) small $N$, large $T$, monthly OECD dataset with the following characteristics:

$$
N=15, T=300, \sigma_{x, i} \sim U[0.0069 \mp 0.0019], \sigma_{u, i}=0.0329 \forall i
$$

This design allows for heterogeneity in the variance of $x_{i t}$ but not $u_{i t}$. The simulations results are based on $R=10,000$ replications. ${ }^{3}$

\subsection{Properties of the panel estimators}

Three estimators based on static linear regressions are considered: the mean group (MG) estimator or average of the group specific estimates suggested in Pesaran and Smith (1995), the pooled OLS (POLS) estimator, and the fixed effects (FE) or 'within' estimator. In each case the conventional standard errors are calculated and the (true) hypothesis that the coefficient of $x_{i t}$ equals unity is tested. The details of the estimators are set out in an Appendix. The asymptotic (large $N$, large $T$ ) properties of the two pooled estimators in the $I(1)$ error case are established in Phillips and Moon (1999). The properties of the MG estimator under the same conditions have not been established and so the Monte Carlo results are of additional interest.

With $I(0)$ errors and homogenous slopes, all three provide consistent (large $N$, large $T$ ) estimates of the long run effects of $x$ on $y$. The vari-

\footnotetext{
${ }^{2}$ The standard deviation estimate $\hat{\sigma}_{x}=0.25$ has been obtained from the price differential data $\left\{d_{i t}\right\}$ as $\hat{\sigma}_{x}=\sqrt{\sum_{i} \sum_{t}\left(\Delta d_{i t}-\overline{\Delta d_{i}}\right)^{2} /(N T-N)}$ and $\hat{\sigma}_{u}$ is analogously obtained from the real exchange rates.

${ }^{3}$ The simulations were programmed in GAUSS 3.2. No initial observations are discarded, $T_{0}=0$, and $x_{i 0}=0 \forall i$ which amounts to using $\tilde{x}_{i t}=x_{i t}-x_{i 0}$ for any $x_{i 0}$.
} 
ance of the MG estimator,

$$
\sigma^{2}\left(\widehat{\beta}^{M G}\right)=\frac{\sigma_{u}^{2}}{N^{2}} E\left(\sum_{i=1}^{N} S_{i}^{-1}\right)=\frac{\sigma_{u}^{2}}{N^{2}} \sum_{i=1}^{N} \frac{6}{\left(T^{2}-1\right) \sigma_{x, i}^{2}},
$$

is greater than or equal to the variance of the $\mathrm{FE}$ estimator,

$$
\sigma^{2}\left(\widehat{\beta}^{F E}\right)=\sigma_{u}^{2} E\left(\sum_{i=1}^{N} S_{i}\right)^{-1}=\frac{6 \sigma_{u}^{2}}{\sigma_{x}^{2} N\left(T^{2}-1\right)},
$$

where $S_{i}=\sum_{t=1}^{T} \widetilde{x}_{i t}^{2}, \tilde{x}_{i t}=x_{i t}-\bar{x}_{i}$, and $\sigma_{x}^{2}=N^{-1} \sum_{i=1}^{N} \sigma_{x, i}^{2}$. If $S_{i}=S$, they are both equally efficient. The most efficient estimator is POLS because the intercepts and slopes are identical and, since there is no serial correlation or heteroskedasticity in the errors, conventional standard errors will be correct. The variance of POLS is:

$$
\sigma^{2}\left(\hat{\beta}^{\text {POLS }}\right)=\frac{6 \sigma_{u}^{2}}{\sigma_{x}^{2}(3 N T-2 T-1)(T+1)}
$$

More generally, these estimators measure different long run parameters. The MG provides estimates of the average long run parameter given by the average over groups of the ratio of the covariance to the variance:

$$
\widehat{\beta}^{M G}=N^{-1} \sum_{i=1}^{N}\left(\frac{\sum_{t=1}^{T} \widetilde{y}_{i t} \widetilde{x}_{i t}}{\sum_{t=1}^{T} \widetilde{x}_{i t}^{2}}\right)=N^{-1} \sum_{i=1}^{N} \widehat{\beta}_{i} .
$$

while the two pooled estimators provide estimates of the long run average parameter. In the FE case the latter is given by the ratio of these averages:

$$
\widehat{\beta}^{F E}=\frac{N^{-1} \sum_{i=1}^{N}\left(\sum_{t=1}^{T} \widetilde{y}_{i t} \widetilde{x}_{i t}\right)}{N^{-1} \sum_{i=1}^{N}\left(\sum_{t=1}^{T} \widetilde{x}_{i t}^{2}\right)}
$$

In general, these will differ even as $N, T$ go to infinity. To see the relationship between them, note that the FE estimator can be written as a weighted average of the individual estimates:

$$
\widehat{\beta}^{F E}=\sum_{i=1}^{N}\left(\frac{S_{i}}{\sum_{i=1}^{N} S_{i}}\right) \widehat{\beta}_{i}=\sum_{i=1}^{N} w_{i} \widehat{\beta}_{i} .
$$


Hence, the difference between $\widehat{\beta}^{M G}$, the unweighted average, and $\widehat{\beta}^{F E}$, the weighted average, will depend on the covariance between the $\widehat{\beta}_{i}$ and the weights, $w_{i}$. They will coincide when $S_{i}=S$ or the $w_{i}$ are independent of the $\hat{\beta}_{i}$. In Section 4 our DGP for the heterogeneous case assumes a positive dependence between the $w_{i}$ and the $\hat{\beta}_{i}$, and accordingly we expect the long run average coefficient to exceed the average long run.

In the $I(1)$ error, no-cointegration case, Phillips and Moon (1999) show that the POLS and FE estimators are consistent estimators of the long run average effect with a convergence rate of $\sqrt{N}$. In this case conventional standard errors for the pooled and fixed effect estimators are wrong and Phillips and Moon provide the correct asymptotic formulae for the levels regression in a number of cases. The performance of these asymptotic standard errors is important but we have left investigation of them as a matter for further research. This is partly because as yet they are rarely used in practice and partly because one needs to know the DGP to be able to identify the appropriate formulae for the standard errors. If one knew that the errors were $I(1)$, the appropriate estimator would be POLS on first differences which would have a variance of $\sigma_{u}^{2} / \sigma_{x}^{2} N T$. In practice one does not know whether there is cointegration or not and pre-testing is rarely unambiguous, particularly in the case of a mix of cointegrating and non-cointegrating relationships or near unit root processes.

\section{Homogeneous slope coefficients}

The empirical distributions of the computed panel estimates and $t$-statistics (testing that the long run effect of $x$ on $y$ is equal to unity) are characterized by their mean, sample standard deviation $(S S D)$, minimum and maximum, median, and moment coefficients of skewness and excess kurtosis in Table 1.

[Table 1 around here]

In the $\mathrm{C}$ case, all three estimators seem unbiased with distributions that are centred on unity and close to normal. A ranking in terms of efficiency based on the $S S D$ indicates that POLS is best, followed by FE and then MG. This is exactly as expected from theory and the $S S D$ for the FE and POLS are very similar to their theoretical standard errors. The $t$-statistics have zero mean and unit standard deviation as they should, suggesting reasonably accurate inference. 
In the NC case Table 1 shows that all three estimators remain unbiased confirming the asymptotic results for the pooled estimators and suggesting that the MG is also consistent. However, their standard deviations are much larger than with cointegration. The lack of cointegration causes a much greater deterioration in Panel II, dispersion increases by a factor of between 60 (MG and FE) and 170 (POLS), than in Panel I where dispersion increases by a factor of between 4 and 14. Although the estimates are unbiased, the dispersion in Panel II is such that the estimates would be of little practical use. The efficiency ranking is now FE, followed by MG and POLS. There are a number of other interesting features. The increase in dispersion of the POLS estimates caused by $I(1)$ errors greatly exceeds that of the FE and the latter exceeds marginally that of the MG estimates. Although the true intercepts are zero and both $u_{i t}$ and $x_{i t}$ have expected values of zero, in particular samples they can have very different means since both are $I(1)$. The superiority of the FE estimator in terms of efficiency suggests that using deviations from the group mean reduces this problem substantially.

Inference properties are examined in more detail in Table 2.

[Table 2 around here]

This table gives the empirical size $\left(p_{\alpha}\right)$ and critical values $\left(\hat{z}_{\alpha}\right)$ at a nominal level $\alpha=5 \%$ for the $t$-tests. The former is calculated using the (theoretical) asymptotic critical values of a standard normal normal distribution, $p_{\alpha}=$ $\left\{\#\left|t_{\beta}^{j}\right| \geq 1.96\right\} / R$. Since the empirical distribution of $t_{\beta^{k}}$ is approximately symmetric (see Table 1 ), the empirical critical values $\hat{z}_{\alpha}$ are calculated as the value of the $(1-\alpha / 2)$-quantile.

Table 2 confirms that the $t$-tests are approximately correctly sized for all three estimators for both panels in the $\mathrm{C}$ case, though the MG is a little oversized for Panel II using asymptotic critical values. This is not surprising since it has only 14 degrees of freedom and the empirical critical value of 2.17 is close to the appropriate critical value of 2.145 from the $t$-distribution. In the $\mathrm{NC}$ case, the MG tests retain the correct size while the FE and POLS estimators show massive size distortions. The FE size distortion is smaller than POLS for both panels and of a similar order of magnitude to that reported in Kao's (1999) analysis. The size characteristics are not surprising since the conventional standard error formulae for POLS and FE are incorrect with $I(1)$ errors, while that for the MG estimator, which uses the cross-section distribution of the estimates, remains appropriate. 
The empirical distribution function (EDF) of the $t$-statistic for the three estimators corroborates these findings. Figure 1 plots the EDF for Panel II in the $I(0)$ and $I(1)$ error case.

[Figure 1 around here]

Figure 1(A) shows that the EDF of the $t$-statistic for the three estimators is very close to that of a standard normal. By contrast, Figure 1(B) shows that, while the EDF of the $t$-statistic for the MG estimator is indistinguishable from that of a standard normal, that of the POLS and FE has considerably fatter tails. The EDFs for Panel I are very similar to those represented in Figure 1.

We investigate the sensitivity of the results to panel dimension, $X 1=$ $(N, T)$, and regressor and innovation standard deviations, $X 2=\left(\sigma_{x}, \sigma_{u}\right)$, by repeating the simulations for different values of $X 1$ and $X 2$. The results are then used as the dependent variable in a regression on the relevant values of $X 1$ and $X 2$. The individual Monte Carlo simulations use $R=500$ replications. ${ }^{4}$

First consider the innovation standard deviations $\sigma_{x, i}$ and $\sigma_{u, i}$ where the former can be viewed as the 'signal' and the latter as the 'noise'. Panel I specifications are used for the individual Monte Carlo replications, $N=30$, $T=25$, and $\sigma_{x, i}^{0}=.25$ and $\sigma_{u, i}^{0}=.14 \forall i$ (where the subscript $i$ is hereafter dropped for simplicity). Eight subsequent values for the latter are generated as $\sigma_{x}^{j}=0.25-0.031 j$ and $\sigma_{u}^{j}=0.14-0.015 j$, respectively, for $j=1, \ldots, 8$. This gives 81 different signal-noise ratio combinations varying from $\sigma_{x} / \sigma_{u}$ $=.08$ for $\sigma_{x}=.002$ and $\sigma_{u}=.14$ to $\sigma_{x} / \sigma_{u}=70$ for $\sigma_{x}=.25$ and $\sigma_{u}=.02$.

To explore the effect of the signal-to-noise ratio on the bias and dispersion of the $M G, P O L S$ and $F E$ panel estimators the results from the 81 simulations were used as observations in the regressions:

$$
\begin{aligned}
\ln (\bar{\beta}) & =a+b \ln \sigma_{x}+c \ln \sigma_{u}+v ; \\
\ln S S D(\hat{\beta}) & =a+b \ln \sigma_{x}+c \ln \sigma_{u}+v
\end{aligned}
$$

for both the $\mathrm{C}$ and $\mathrm{NC}$ cases. Since there is no reason to expect the errors of these regressions to be homoskedastic, White's heteroscedasticity-consistent standard errors are used. The results are given in Table 3.

\footnotetext{
${ }^{4}$ Since the main results in Tables 1-2 still hold when the experiments were repeated for $R=500$ this number of replications is adopted to keep computational costs feasible.
} 
[Table 3 around here]

This shows that the $S S D$ is proportional to the noise-to-signal ratio $\left(\sigma_{u} / \sigma_{x}\right)$ with a coefficient close to unity for all three estimators. This explains the different results for Panels I and II.

Now consider the effect of the panel dimensions, $N$ and $T$. The specifications are again based on Panel I, $\sigma_{x, i}=.25 \forall i, \sigma_{u, i}=.14 \forall i$. Let $N, T=\{25,50,75,100,150,200,250,300,350\}$ which gives 81 observations in the regressions:

$$
\begin{aligned}
\ln (\bar{\beta}) & =a+b \ln N+c \ln T+v ; \\
\ln S S D(\hat{\beta}) & =a+b \ln N+c \ln T+v
\end{aligned}
$$

Table 4 reports the results.

[Table 4 around here]

It shows that in the $\mathrm{C}$ case the three estimators are unbiased irrespective of $N$ and $T$ and POLS is more efficient than FE and MG. The SSD for the three estimators falls at rate $T$ as in the pure time series $\mathrm{C}$ case and falls with the group dimension at rate $\sqrt{N}$. In the NC case all three estimators remain unbiased, dispersion still falls at rate $\sqrt{N}$ while it does not change with $T$ as the theory indicates. The asymptotic theory clearly works well in these samples.

\section{Heterogeneous slope coefficients}

In this section the assumption of common slope coefficients is relaxed. We allow $\beta_{i}$ to vary randomly across groups, with $E\left(\beta_{i}\right)=1$. For the POLS and FE estimator this will lead to the presence of an extra $I(1)$ component $\left(\beta_{i}-\right.$ $\beta) x_{i t}$ in the error term and the composite error term will be heteroskedastic. Our model of heterogeneous coefficients introduces dependence between the coefficients and the regressors as follows:

$$
\begin{array}{lll}
\beta_{i}=.75+\sigma_{x, i} ; & \sigma_{x, i} \sim U[0.25 \mp 0.15] \text { (Panel I) } \\
\beta_{i}=.9931+\sigma_{x, i} ; & \sigma_{x, i} \sim U[0.0069 \mp 0.0019] \text { (Panel II). }
\end{array}
$$


This positive dependence should cause the ratio of the average covariance to average variance to exceed the average of the ratio, leading to a difference between the two pooled estimators and the MG. Note that by construction the heterogeneity in Panel I is much larger than in Panel II. However, the heterogeneity in both cases is quite small relative to that typically observed.

The results are reported in Tables 5 and 6

[Tables 5, 6 around here]

In Panel I, where the heterogeneity is large, the mean of the MG estimator remains around unity and the mean of the FE and POLS increases to about 1.06 , in both the $I(0)$ and $I(1)$ case. The effect is in the direction we would expect, given the positive covariance between $\beta_{i}$ and $\sigma_{x, i}$ in our Monte Carlo design, but it is not large in economic terms. It does, however, result in a marked increase in the $t$-ratio for the FE and POLS. This is partly because the null hypothesis is no longer appropriate, based as it is on the average long run, $H_{0}: \beta=1=E\left(\beta_{i}\right)$, rather than the long run average. The dispersion of the $t$-ratio falls below the correct value of unity for the MG estimator but is well above that for the other two. In the $I(0)$ case the efficiency of the MG estimator in the heterogeneous case is identical to that in the homogeneous case. By contrast, the efficiency of the other two estimators falls relative to the homogeneous case. The ranking now becomes FE, MG, POLS rather than POLS, FE, MG. In the $I(1)$ case the dispersion of all three estimators is similar to the homogeneous case. In Panel II, where the heterogeneity is small, the properties of the panel estimators are very similar to the homogeneous case.

Table 6 investigates inference in the heterogeneous case and should be compared with Table 2 for the homogeneous case. In Panel II, where heterogeneity is small, the results are very similar to the homogeneous case. In Panel I, the combination of the inappropriate estimated standard errors and the difference between the hypothesized value and the long run average drive the rejection frequencies of the POLS and FE to almost $100 \%$. In the $I(0)$ case, the size of the MG test is pushed down by the lower than appropriate variance of the $t$-ratio, though it does remarkably well in the $I(1)$ case.

These insights are illustrated graphically by the EDF of the $t$-statistic plotted in Figure 2.

[Figure 2 around here] 
Figure 2(A) illustrates how in the $I(0)$ case the distribution of the POLS and FE departs notably from that of a standard normal in shifting to the right and exhibiting larger dispersion. By contrast, the distribution of the MG $t$-ratio remains fairly close to a standard normal, especiallly in the $I(1)$ case. A comparison of EDFs in Figure 2(B) and Figures 1(A) and 1(B) corroborates the view that the properties of the statistics in panels with small heterogeneity are indistinguishable from those in homogeneous panels.

We estimated response surfaces for Panel I, where the heterogeneity is large, using $\mathrm{R}=500$. Using $N, T=\{25,50,75,100,150,200,250,300,350\}$ we obtain 81 observations to fit functional forms (9) and (10). The results are given in Table 7.

\section{[Table 7 around here]}

In the $I(1)$ error case the results are almost exactly the same as in the homogeneous case, the dispersion of the estimators falls with $\sqrt{N}$ but not with $T$. In the $I(0)$ error case, the MG behaves as it did in the homogeneous case with its dispersion falling with $T \sqrt{N}$. Since every group cointegrates, the estimator for each group and its mean are both superconsistent and so the dispersion of the MG estimator also falls with $T$.

The big change is in the performance of the POLS and FE estimators in the $I(0)$ error case where the dispersion falls with $\sqrt{N}$ but not with $T$. The explanation is that when a homogeneous slope is wrongly imposed the panel does not cointegrate because of the presence of the $I(1)$ term $\left(\beta_{i}-\beta\right) x_{i t}$ in the error. Accordingly the two pooled estimators show the characteristic effects of $I(1)$ errors: virtually no gain in efficiency with increased time-series dimension. The coefficient on $\ln T$ is significantly greater than zero but the estimated values of -0.02 for POLS and -0.08 for FE are very small. Figure 3

plots the evolution of $S S D(\hat{\beta})$ with $T$ as suggested by the estimated response surfaces.

[Figure 3 around here]

The base variation for the MG is larger but for Panel I the MG dominates the POLS for $T>27$ and the FE for $T>31$. If individual groups cointegrate with different coefficients, the penalty for pooling grows rapidly with $T$. 


\section{PPP application}

This section reports the results of estimating a PPP regression using the three estimators. Data on nominal exchange rates and consumer (CPI) and wholesale price indices (WPI) were taken from Datastream for a panel of OECD countries, 1972:1-1998:12. Four panels were constructed using the German mark (DM) and US dollar (US\$) as numeraire and the CPI and WPI price series. ${ }^{5}$

$\mathrm{ADF}$ test results indicated that the unit root null could not be rejected at the $5 \%$ level for the individual real exchange rates in the four panels. ${ }^{6}$ This implies the absence of time series cointegration between $e_{i t}$, the logarithm of the exchange rate and $d_{i t}$, the logarithm of the price differential. However in the light of our small sample findings the long run relationship between the nominal exchange rate and the price differential can be analysed using panel estimators even when there is no cointegration. ${ }^{7}$ We distinguish between two interpretations of PPP. One implies stationary real exchange rates or cointegration between nominal exchange rates and the price differential and is called $\operatorname{PPP}(0)$. The other refers to the case where price differentials are fully reflected in the nominal exchange rate but in the presence of an $\mathrm{I}(1)$ error and is called $\operatorname{PPP}(1)$.

Table 8 reports the dispersion of the parameter estimates of $\hat{\beta}_{i}$.

[Table 8 around here]

The dispersion is very large, much larger than we assumed for Panels I and II in the Monte Carlo. Both the SSD and range of the estimates for the CPI panels exceed those for the WPI panels. Some dispersion would be expected because these are probably spurious regressions, but country specific specification errors must also play a part. As the Monte Carlo results indicated, both lack of cointegration and heterogeneity will distort inference based on

\footnotetext{
${ }^{5}$ The composition of the four panels is slightly different. The CPI panels have 18 countries: Austria, Canada, Denmark, Finland, Germany, Greece, Japan, Netherlands, Sweden, Spain, Switzerland, United Kingdom, United States, Belgium, France, Italy, Norway, Portugal. The WPI panels exclude the latter five countries and include Ireland. Excluding the numeraires this gives $N=17$ and $N=13$ groups, respectively.

${ }^{6}$ Overall there was just one rejection in the four panels. Detailed results are available from the authors on request.

${ }^{7}$ In this section we ignore the problem of cross sectional dependence in panels which is examined in Coakley, Fuertes and Smith (2001).
} 
the pooled estimators and we would expect to over-reject the null $\beta=1$ using the POLS and FE estimators. To control for excessive heterogeneity, the number of standard deviations from the mean, $Z\left(\hat{\beta}_{i}\right)=\left(\hat{\beta}_{i}-\bar{\beta}\right) / \sigma\left(\hat{\beta}_{i}\right)$, is calculated and, using $Z>2$, the following potential outliers in the distribution of $\hat{\beta}_{i}$ are identified: Austria for both DM panels, and Japan and the United Kingdom for the CPI-US\$ and WPI-US\$ panels, respectively. For relatively small $N$, as in this case, the MG estimator is likely to be sensitive to outliers.

The panel results and a $t$-statistic for $\beta=1$ are reported in Table $9 .{ }^{8}$

[Table 9 around here]

Except for the 0.78 MG estimate for the CPI-DM panel, all the estimates lie in the range 0.93-1.1. For the US dollar panels, the MG is higher than the pooled estimates, though the difference is not large. The test based on the MG estimator provides support for the $\operatorname{PPP}(1)$ hypothesis in three of the four panels. ${ }^{9}$ Futhermore, the statistic for the CPI-DM panel at -2.642 represents only a marginal rejection at the $5 \%$ level from a Student- $t$ distribution with 16 degrees of freedom.

By contrast, inference based on the two pooled estimators rejects long run PPP in three out of the four panels with relatively large $t$-statistics. These contrasting results - and in particular the negative verdict on $\mathrm{PPP}(1)$ from the pooled regression estimators - is consistent with our Monte Carlo findings of oversized inference in the $I(1)$ error, heterogeneous slope case. Moreover, since the simulations indicated that inferences based on the MG estimator are appropriate in the latter context, we conclude that the evidence points towards $\mathrm{PPP}(1)$ both for the US dollar and DM panels despite the presence of a stochastic trend in the real exchange rate indicated by the unit root tests.

These results have a number of general implications for applied work. First, one can estimate and test for long run effects in panels even when the variables do not cointegrate. In other words, long run effects are not exclusively associated with cointegrating relationships. On that basis we distinguish between $\operatorname{PPP}(0)$ and $\operatorname{PPP}(1)$ and provide estimates and test results

\footnotetext{
${ }^{8}$ Note that the nominal exchange rate variable had to be normalised on the base year (1995) exchange rate for the POLS regression.

${ }^{9}$ The same qualitative results are obtained after discarding the countries identified earlier as outliers.
} 
for the latter case. Secondly, since panels permit consistent estimation of a regression parameter even in the presence of an $I(1)$ error, it follows that one cannot make inferences about the nature of the error from the estimated coefficients. The fact that in panel PPP regressions the coefficient of the price level differential is unity does not imply that real exchange rates are necessarily stationary. Given this it would be wise to use a range of alternative estimators and examine and interpret the differences between them. Finally conclusions about efficiency and hypothesis testing are further complicated by the fact that the pooled and mean group estimators are estimating different long run parameters. Thus it is important for researchers to be clear about the difference between the average long run or the long run average as potential measures of a long run relationship.

\section{Conclusions}

This paper has used Monte Carlo simulations to examine how the aymptotic (large $N$ large $T$ ) results on the properties of pooled estimators in Phillips and Moon (1999) perform in panels which are typical of applied, particularly PPP, research. We also consider the performance of an alternative estimator, the mean group. The experiments confirm that the asymptotic results hold fairly well for small sample sizes and hence apply in empirically relevant situations. Both the pooled and mean group estimators appear unbiased, with dispersion that falls at rate $\sqrt{N}$ even when the error term is $I(1)$ and therefore the individual time-series regressions are spurious. The efficiency of the estimators depends on the ratio of the error innovation to the regressor innovation and, in some circumstances, the variance of the estimators can be very large. The simulations also confirm the asymptotic result that conventional standard errors for the pooled estimators are seriously misleading and inference based on them in unreliable. Interestingly, the standard errors for the mean group estimator are broadly correct for all the data generating processes considered.

The results for the $I(1)$ case are very similar irrespective of whether the regression parameters are heterogeneous or homogeneous. In the $I(0)$-error and heterogeneous- $\beta$ case, the standard error of the mean group estimator declines at rate $T \sqrt{N}$. However, because heterogeneity induces an extra $I(1)$ term in the disturbance, the standard errors of the pooled estimators declines only at rate $\sqrt{N}$ as in the $I(1)$ error case. While the pooled estimators 
may have an efficiency advantage over the mean group estimator in small $T$ samples, they rapidly lose this as $T$ grows. Finally in the light of these findings, the evidence suggests that the PPP hypothesis - that nominal exchange rates and price differentials move one-for-one in the long run seems to hold even if real exchange rates are subject to permanent shocks.

\section{ACKNOWLEDGEMENTS}

We are grateful to Haris Psaradakis, Steve Satchell and Martin Sola for help with earlier drafts. We retain responsibility for any remaining errors. 


\section{Appendix: Panel Estimators}

Denote

$$
\begin{aligned}
& \bar{y}_{i}=T^{-1} \sum_{t=1}^{T} y_{i t} ; \bar{y}=(N T)^{-1} \sum_{i=1}^{N} \sum_{t=1}^{T} y_{i t} \\
& \widetilde{y}_{i t}=y_{i t}-\bar{y}_{i}
\end{aligned}
$$

and define analogous measures for $x_{i t}$.

i) Mean group (MG) estimator

Separate OLS regressions are run for each group $i=1,2, \ldots, N$ :

$$
y_{i t}=\alpha_{i}+\beta_{i} x_{i t}+u_{i t}
$$

and from the individual estimates and their standard deviation:

$$
\begin{gathered}
\hat{\beta}_{i}=\sum_{t=1}^{T} \widetilde{y}_{i t} \widetilde{x}_{i t} / \sum_{t=1}^{T} \widetilde{x}_{i t}^{2} \\
\sigma\left(\hat{\beta}_{i}\right)=\sqrt{\sum_{i=1}^{N}\left(\hat{\beta}_{i}-\bar{\beta}\right)^{2} /(N-1),}
\end{gathered}
$$

we compute the MG estimator, its standard error and $t$ statistic for the null of $\beta=1$ against the alternative $\beta \neq 1$ :

$$
\begin{gathered}
\widehat{\beta}^{M G}=\bar{\beta}=\sum_{i=1}^{N} \hat{\beta}_{i} / N, \\
\operatorname{se}\left(\widehat{\beta}^{M G}\right)=\sigma\left(\hat{\beta}_{i}\right) / \sqrt{N} \\
t\left(\widehat{\beta}^{M G}\right)=\left(\widehat{\beta}^{M G}-1\right) / \operatorname{se}\left(\widehat{\beta}^{M G}\right) .
\end{gathered}
$$

ii) Pooled OLS (POLS) estimator

The NT observations are pooled to fit the OLS regression: 


$$
y_{i t}=\alpha+\beta x_{i t}+u_{i t},
$$

The corresponding POLS estimates are:

$$
\begin{gathered}
\hat{\beta}^{P O L S}=\frac{\sum_{i=1}^{N} \sum_{t=1}^{T}\left(y_{i t}-\bar{y}\right)\left(x_{i t}-\bar{x}\right)}{\sum_{i=1}^{N} \sum_{t=1}^{T}\left(x_{i t}-\bar{x}\right)^{2}} \\
\operatorname{se}\left(\hat{\beta}^{P O L S}\right)=\frac{s}{\sqrt{\sum_{i=1}^{N} \sum_{t=1}^{T}\left(x_{i t}-\bar{x}\right)^{2}}} \text { where } s^{2}=\frac{\sum_{i=1}^{N} \sum_{t=1}^{T} \hat{u}_{i t}^{2}}{(N T-2)} \\
t\left(\hat{\beta}^{P O L S}\right)=\left(\hat{\beta}^{P O L S}-1\right) / \operatorname{se}\left(\hat{\beta}^{P O L S}\right) .
\end{gathered}
$$

iii) Fixed effects (FE) estimator

We pool the NT observations to fit the OLS regression:

$$
y_{i t}=\alpha_{i}+\beta x_{i t}+u_{i t}
$$

The corresponding FE estimates are:

$$
\begin{gathered}
\hat{\beta}^{F E}=\frac{\sum_{i=1}^{N} \sum_{t=1}^{T} \widetilde{y}_{i t} \widetilde{x}_{i t}}{\sum_{i=1}^{N} \sum_{t=1}^{T} \widetilde{x}_{i t}^{2}} \\
\operatorname{se}\left(\hat{\beta}^{F E}\right)=\frac{s}{\sqrt{\sum_{i=1}^{N} \sum_{t=1}^{T} \widetilde{x}_{i t}^{2}}} \text { where } s^{2}=\frac{\sum_{i=1}^{N} \sum_{t=1}^{T} \hat{u}_{i t}^{2}}{N T-(N+1)} \\
t\left(\hat{\beta}^{F E}\right)=\left(\hat{\beta}^{F E}-1\right) / \operatorname{se}\left(\hat{\beta}^{F E}\right) .
\end{gathered}
$$




\section{References}

Baltagi, B.H. and J.M. Griffin (1997) Pooled Estimators Versus their Heterogeneous Counterparts in the Context of the Dynamic Demand for Gasoline, Journal of Econometrics, 77, 303-327.

Baltagi, B.H. and C. Kao (2000) Nonstationary Panels, Cointegration in Panels and Dynamic Panels: A Survey, Advances in Econometrics 15, Forthcoming.

Boyd, D. and R. P. Smith (1999) Testing for Purchasing Power Parity: Econometric Issues and an Application to Developing Countries, Manchester School 67, 287-303.

Boyd, D. and R.P. Smith (2000) Some Econometric Issues in Measuring the Monetary Transmission Mechanism, with an Application to Developing Countries, Birkbeck College Discussion Paper in Economics 15/2000.

Coakley, J., and A.M. Fuertes (2000) Is There a Base Currency Effect in Long Run PPP? International Journal of Finance and Economics 5, 253-263.

Coakley, J., and A.M. Fuertes (2001) Nonparametric Cointegration Analysis of Real Exchange Rates, Applied Financial Economics 11, 1-8.

Coakley, J., A.M. Fuertes, and R. Smith (2001) Between Group Dependence in PPP Equations and its Causes: A Principal Components Approach, Mimeo, Birkbeck College, University of London.

Higgins, M. and E. Zakrajšek (1999) Purchasing Power Parity: Three Stakes in the Heart of the Unit Root Null, Mimeo, Federal Reserve Bank of New York.

Kao, C. (1999) Spurious Regression and Residual-Based Tests for Cointegration in Panel Data, Journal of Econometrics 90, 1-44.

O'Connell, P.J.G. (1998) The Overvaluation of Purchasing Power Parity. Journal of International Economics 44: 1-19.

Pedroni, P. (1997) Cross Sectional Dependence in Cointegration Tests of Purchasing Power Parity in Panels, Mimeo, Indiana University.

Pesaran, M.H. and R. Smith (1995) Estimating Long Run Relationships from Dynamic Heterogeneous Panels, Journal of Econometrics 68, 79-113.

Phillips, P.C.B., and H.R. Moon (1999) Linear Regression Theory for Nonstationary Panel Data, Econometrica 67, 1057-1111.

Phillips, P.C.B., and H.R. Moon (2000) Nonstationary Panel Data Analysis: An Overview of Some Recent Developments, Econometric Reviews 19, 263-286. 
Taylor, A.M. (2001) Potential Pitfalls for the Purchasing Power Parity Puzzle? Sampling and Specification Biases in Mean-Reversion Tests of the Law of One Price, Econometrica, 69, 473-498. 
Table 1 Summary statistics (Homogeneous slope)

A) PANEL I

\begin{tabular}{|c|c|c|c|c|c|c|c|}
\hline & Mean & $S S D$ & Min. & Max. & Median & Skew. & Kurt-3 \\
\hline \multicolumn{8}{|c|}{ i) $I(0)$ errors } \\
\hline$\beta^{M G}$ & 1.0001 & .0164 & .9356 & 1.0617 & 1.0003 & .0138 & .1634 \\
\hline$\beta^{P O L S}$ & 1.0001 & .0056 & .9782 & 1.0244 & 1.0002 & .0249 & .1570 \\
\hline$\beta^{F E}$ & 1.0001 & .0096 & .9627 & 1.0359 & 1.0002 & .0159 & .0383 \\
\hline$t_{\beta^{M G}}$ & .0035 & 1.0205 & -4.2151 & 4.1064 & .0211 & -.0288 & .0494 \\
\hline$t_{\beta^{P O L S}}$ & .0193 & .9997 & -3.7318 & 3.7177 & .0266 & .0198 & -.0350 \\
\hline$t_{\beta^{F E}}$ & .0149 & .9945 & -3.7473 & 3.4870 & .0156 & .0085 & -.0327 \\
\hline \multicolumn{8}{|c|}{ ii) $I(1)$ errors } \\
\hline$\beta^{M G}$ & 1.0002 & .0734 & .7044 & 1.3548 & 1.0004 & -.0124 & .0933 \\
\hline$\beta^{P O L S}$ & 1.0007 & .0785 & .6598 & 1.3183 & 1.0005 & -.0219 & .1494 \\
\hline$\beta^{F E}$ & 1.0004 & .0601 & .7429 & 1.2056 & 1.0000 & -.0191 & .1211 \\
\hline$t_{\beta^{M G}}$ & .0036 & 1.0309 & -4.8001 & 4.2294 & .0046 & .0127 & .0439 \\
\hline$t_{\beta} P O L S$ & .0502 & 4.1573 & -20.0027 & 16.4573 & .0298 & -.0023 & .1588 \\
\hline$t_{\beta^{F E}}$ & .0128 & 3.1110 & -13.1621 & 12.2589 & .0006 & -.0042 & .1143 \\
\hline
\end{tabular}

B) PANEL II

\begin{tabular}{|c|c|c|c|c|c|c|c|}
\hline & Mean & $S S D$ & Min. & Max. & Median & Skew. & Kurt-3 \\
\hline \multicolumn{8}{|c|}{ i) $I(0)$ errors } \\
\hline$\beta^{M G}$ & 1.0002 & .0140 & .9432 & 1.0640 & 1.0002 & .0137 & .1307 \\
\hline$\beta^{P O L S}$ & 1.0001 & .0062 & .9716 & 1.0298 & .9999 & .0583 & .4357 \\
\hline$\beta^{F E}$ & 1.0002 & .0103 & .9512 & 1.0365 & 1.0001 & .0225 & .1876 \\
\hline$t_{\beta^{M G}}$ & .0183 & 1.0769 & -4.7639 & 4.7760 & .0152 & -.0151 & .2548 \\
\hline$t_{\beta^{P O L S}}$ & .0116 & 1.0044 & -4.4018 & 3.7264 & -.0147 & .0273 & .0441 \\
\hline$t_{\beta^{F E}}$ & .0145 & 1.0031 & -4.3065 & 3.3878 & .0055 & .0118 & -.0102 \\
\hline \multicolumn{8}{|c|}{ ii) $I(1)$ errors } \\
\hline$\beta^{M G}$ & .9978 & .8341 & -2.4154 & 4.1996 & .9883 & .0192 & .1332 \\
\hline$\beta^{P O L S}$ & .9949 & 1.0357 & -2.9439 & 6.1529 & .9815 & .0182 & .2125 \\
\hline$\beta^{F E}$ & .9994 & .7779 & -1.6974 & 4.0661 & 1.0047 & -.0135 & .0761 \\
\hline$t_{\beta^{M G}}$ & -.0035 & 1.0807 & -5.0416 & 4.9543 & -.0154 & .0084 & .4785 \\
\hline$t_{\beta^{P O L S}}$ & -.0149 & 14.8476 & -66.8688 & 64.7852 & -.2580 & .0392 & .2818 \\
\hline$t_{\beta^{F E}}$ & .0072 & 11.0579 & -42.1452 & 42.3121 & .0652 & -.0011 & .1088 \\
\hline
\end{tabular}


Table 2 Empirical size and critical values

\begin{tabular}{|c|c|c|c|c|c|c|c|c|}
\hline \multicolumn{5}{|c|}{ PANEL I } & \multicolumn{4}{|c|}{ PANEL II } \\
\hline & $I(0)$ & rrors & $I(1)$ & rrors & $I(0)$ & errors & $I(1)$ & errors \\
\hline & $p_{.05}$ & $\hat{z}_{.05}$ & $p_{.05}$ & $\hat{z}_{.05}$ & $p_{.05}$ & $\hat{z}_{.05}$ & $p_{.05}$ & $\hat{z}_{.05}$ \\
\hline$\overline{M G}$ & 5.32 & 1.98 & 5.77 & 2.06 & 7.07 & 2.17 & 6.82 & 2.16 \\
\hline POLS & 5.06 & 1.99 & 64.02 & 8.21 & 4.94 & 1.99 & 89.50 & 29.69 \\
\hline$F E$ & 4.61 & 1.94 & 52.37 & 6.17 & 4.88 & 1.96 & 85.66 & 21.81 \\
\hline
\end{tabular}


Table 3 Response surfaces for innovation variances

\begin{tabular}{|c|c|c|c|c|c|c|}
\hline \multicolumn{7}{|c|}{ i) $I(0)$ errors } \\
\hline & \multicolumn{2}{|c|}{$M G$} & \multicolumn{2}{|c|}{ POLS } & \multicolumn{2}{|c|}{$F E$} \\
\hline & $\bar{\beta}$ & $S S D(\hat{\beta})$ & $\bar{\beta}$ & $S S D(\hat{\beta})$ & $\bar{\beta}$ & $S S D(\hat{\beta})$ \\
\hline$\hat{a}$ & $\begin{array}{c}-.0064 \\
(-1.221)\end{array}$ & $\begin{array}{c}-3.737 \\
(-232.005)\end{array}$ & $\begin{array}{l}-.0011 \\
(-.578)\end{array}$ & $\begin{array}{c}-4.5278 \\
(-272.833)\end{array}$ & $\begin{array}{l}-.0055 \\
(-1.040)\end{array}$ & $\begin{array}{c}-4.0161 \\
(-231.047)\end{array}$ \\
\hline$\hat{b}$ & $\begin{array}{c}7.84 \mathrm{E}-05 \\
(.029)\end{array}$ & $\begin{array}{c}-.9994 \\
(-353.832)\end{array}$ & $\begin{array}{l}-.0004 \\
(-.299)\end{array}$ & $\begin{array}{c}-.9955 \\
(-364.186)\end{array}$ & $\begin{array}{l}.0011 \\
(.383)\end{array}$ & $\begin{array}{c}-1.0001 \\
(-389.834)\end{array}$ \\
\hline$\hat{c}$ & $\begin{array}{l}-.0024 \\
(-1.028)\end{array}$ & $\begin{array}{c}.9958 \\
(183.203)\end{array}$ & $\begin{array}{l}-.0001 \\
(-.133)\end{array}$ & $\begin{array}{c}1.0088 \\
(184.466)\end{array}$ & $\begin{array}{l}-.0029 \\
(-1.060)\end{array}$ & $\begin{array}{c}.9996 \\
(182.441)\end{array}$ \\
\hline $\bar{R}^{2}$ & -.0133 & .9996 & -.0179 & .9995 & .0009 & .9997 \\
\hline \multicolumn{7}{|c|}{ ii) $I(1)$ errors } \\
\hline$\hat{a}$ & $\begin{array}{l}.0038 \\
(.290)\end{array}$ & $\begin{array}{c}-2.1668 \\
(-115.120)\end{array}$ & $\begin{array}{l}-.0346 \\
(-.738)\end{array}$ & $\begin{array}{c}-1.8780 \\
(-100.464)\end{array}$ & $\begin{array}{l}.0034 \\
(.311)\end{array}$ & $\begin{array}{c}-2.1512 \\
(-112.611)\end{array}$ \\
\hline$\hat{b}$ & $\begin{array}{l}.0003 \\
(.024)\end{array}$ & $\begin{array}{c}-.9997 \\
(-506.340)\end{array}$ & $\begin{array}{l}.0361 \\
(.938)\end{array}$ & $\begin{array}{c}-.9986 \\
(-478.090)\end{array}$ & $\begin{array}{l}-.0086 \\
(-1.219)\end{array}$ & $\begin{array}{c}-.9965 \\
(-380.061)\end{array}$ \\
\hline$\hat{c}$ & $\begin{array}{l}.0010 \\
(.108)\end{array}$ & $\begin{array}{c}.9955 \\
(174.951)\end{array}$ & $\begin{array}{l}-.0407 \\
(-1.209)\end{array}$ & $\begin{array}{c}1.0002 \\
(160.929)\end{array}$ & $\begin{array}{c}.0074 \\
(1.102)\end{array}$ & $\begin{array}{c}.9983 \\
(165.716)\end{array}$ \\
\hline $\bar{R}^{2}$ & -.0255 & .9997 & .0571 & .9996 & .0965 & .9995 \\
\hline
\end{tabular}

Notes: $t$-ratios in parentheses. Panel I specifications are used. Functional forms: $\ln (\bar{\beta})=a+b \ln N+c \ln T+v$

$\ln S S D(\hat{\beta})=a+b \ln N+c \ln T+v$ 
Table 4 Response surfaces for panel dimensions

\begin{tabular}{ccccccc}
\hline \multicolumn{2}{c}{$i) I(0)$ errors } & \multicolumn{2}{c}{ POLS } & \multicolumn{2}{c}{$F E$} \\
\hline \multicolumn{2}{c}{$\bar{c}$ G } & $S S D(\hat{\beta})$ & $\bar{\beta}$ & $S S D(\hat{\beta})$ & $\bar{\beta}$ & $S S D(\hat{\beta})$ \\
\hline$\hat{a}$ & -.0006 & .6424 & -.0002 & -.1631 & -.0005 & .3538 \\
& $(-1.692)$ & $(26.067)$ & $(-1.595)$ & $(-5.413)$ & $(-1.938)$ & $(14.453)$ \\
$\hat{b}$ & $6.37 \mathrm{E}-5$ & -.4996 & $7.78 \mathrm{E}-6$ & -.5149 & $3.93 \mathrm{E}-5$ & -.5053 \\
& $(1.722)$ & $(-124.493)$ & $(.644)$ & $(-117.138)$ & $(1.621)$ & $(-112.375)$ \\
$\hat{c}$ & $6.13 \mathrm{E}-5$ & -1.0064 & $2.85 \mathrm{E}-5$ & -.9980 & $5.54 \mathrm{E}-5$ & -1.0017 \\
& $(1.463)$ & $(-263.821)$ & $(2.278)$ & $(-220.859)$ & $(1.875)$ & $(-238.169)$ \\
$\bar{R}^{2}$ & .1231 & .9989 & .1331 & .9987 & .1487 & .9988 \\
\hline$i i)$ & $I(1)$ errors & & & & & \\
\hline$\hat{a}$ & .0005 & -1.0262 & -.0039 & -.7097 & -.0015 & -1.0316 \\
& $(.236)$ & $(-45.205)$ & $(-1.193)$ & $(-33.257)$ & $(-.751)$ & $(-37.353)$ \\
$\hat{b}$ & $6.42 \mathrm{E}-5$ & -.5001 & .0005 & -.5121 & .0002 & -.5024 \\
& $(.214)$ & $(-132.449)$ & $(1.028)$ & $(-131.506)$ & $(.569)$ & $(-117.594)$ \\
$\hat{c}$ & -.0002 & -.0039 & .0003 & -.0013 & .0001 & .0003 \\
& $(-.970)$ & $(-.957)$ & $(.688)$ & $(-.384)$ & $(.645)$ & $(.085)$ \\
$\bar{R}^{2}$ & -.0161 & .9943 & .0109 & .9953 & -.0135 & .9944 \\
\hline
\end{tabular}

Notes: $t$-ratios in parentheses. Panel I specifications are used. Functional forms: $\ln (\bar{\beta})=a+b \ln N+c \ln T+v ;$

$\ln S S D(\hat{\beta})=a+b \ln N+c \ln T+v$ 
Table 5 Summary statistics (Heterogeneous slopes)

A) PANEL I

\begin{tabular}{|c|c|c|c|c|c|c|c|}
\hline & Mean & $S S D$ & Min & $\operatorname{Max}$ & Median & Skew & Kurt-3 \\
\hline \multicolumn{8}{|c|}{ i) $I(0)$ errors } \\
\hline$\beta^{M G}$ & 1.0070 & .0164 & .9286 & 1.0691 & 1.0071 & .0269 & .0541 \\
\hline$\beta^{P O L S}$ & 1.0598 & .0165 & .9941 & 1.1133 & 1.0598 & -.0264 & -.1806 \\
\hline$\beta^{F E}$ & 1.0607 & .0152 & 1.0037 & 1.1115 & 1.0607 & -.0228 & -.0405 \\
\hline$t_{\beta^{M G}}$ & .3572 & .7453 & -1.8188 & 3.9983 & .3082 & .4129 & .2447 \\
\hline$t_{\beta^{P O L S}}$ & 10.1642 & 3.4301 & -.8285 & 24.9962 & 9.9166 & .4080 & .1951 \\
\hline$t_{\beta^{F E}}$ & 6.3322 & 1.8772 & .3493 & 15.5978 & 6.2277 & .3202 & .1885 \\
\hline \multicolumn{8}{|c|}{ ii) $I(1)$ errors } \\
\hline$\beta^{M G}$ & 1.0093 & .0788 & .7226 & 1.3374 & 1.0088 & .0184 & .0950 \\
\hline$\beta^{P O L S}$ & 1.0639 & .0793 & .7341 & 1.3525 & 1.0639 & -.0686 & .1658 \\
\hline$\beta^{F E}$ & 1.0642 & .0606 & .8178 & 1.3164 & 1.0648 & -.0435 & .0024 \\
\hline$t_{\beta^{M G}}$ & .1471 & 1.0078 & -3.5733 & 4.2683 & .1148 & .1834 & .0451 \\
\hline$t_{\beta^{P O L S}}$ & 3.4901 & 4.2785 & -15.7760 & 20.8615 & 3.4371 & .0643 & .1697 \\
\hline$t_{\beta^{F E}}$ & 3.3933 & 3.2026 & -8.6983 & 17.7462 & 3.2834 & .0621 & -.0133 \\
\hline
\end{tabular}

B) PANEL II

\begin{tabular}{|c|c|c|c|c|c|c|c|}
\hline & Mean & $S S D$ & Min & $\operatorname{Max}$ & Median & Skew & Kurt-3 \\
\hline \multicolumn{8}{|c|}{ i) $I(0)$ errors } \\
\hline$\beta^{M G}$ & .9999 & .0140 & .9447 & 1.0551 & .9999 & -.0215 & .1747 \\
\hline$\beta^{P O L S}$ & 1.0004 & .0060 & .9740 & 1.0270 & 1.0003 & .0036 & .2414 \\
\hline$\beta^{F E}$ & 1.0002 & .0101 & .9583 & 1.0385 & 1.0004 & -.0449 & .2203 \\
\hline$t_{\beta^{M G}}$ & -.0063 & 1.0855 & -4.9365 & 4.4814 & -.00497 & -.0532 & .3118 \\
\hline$t_{\beta^{P O L S}}$ & .0654 & 1.0024 & -3.6226 & 3.4534 & .0506 & .0119 & -.0942 \\
\hline$t_{\beta^{F E}}$ & .0237 & 1.0172 & -3.6116 & 3.5886 & .0334 & -.0361 & .0637 \\
\hline \multicolumn{8}{|c|}{ ii) $I(1)$ errors } \\
\hline$\beta^{M G}$ & 1.0109 & .7798 & -2.0940 & 5.0838 & 1.0082 & -.0009 & .1457 \\
\hline$\beta^{P O L S}$ & 1.0148 & 1.0021 & -2.9602 & 5.0172 & 1.0178 & -.0161 & .2390 \\
\hline$\beta^{F E}$ & 1.0070 & .7442 & -1.8474 & 4.1161 & 1.0087 & -.0209 & .0753 \\
\hline$t_{\beta^{M G}}$ & .0124 & 1.0684 & -4.2912 & 5.8753 & .0111 & -.0134 & .3799 \\
\hline$t_{\beta^{P O L S}}$ & .2189 & 14.9120 & -56.8570 & 64.8759 & .2638 & -.0015 & .2150 \\
\hline$t_{\beta F E}$ & .0983 & 10.9928 & -42.7103 & 50.0137 & .1273 & -.0201 & .1104 \\
\hline
\end{tabular}


Table 6 Empirical size and critical values (Heterogenous slopes)

\begin{tabular}{|c|c|c|c|c|c|c|c|c|}
\hline \multicolumn{5}{|c|}{ PANEL I } & \multicolumn{4}{|c|}{ PANEL II } \\
\hline & $I(0)$ & rrors & $I(1)$ & errors & $I(0)$ & errors & $I(1)$ & errors \\
\hline & $p_{.05}$ & $\hat{z}_{.05}$ & $p_{.05}$ & $\hat{z}_{.05}$ & $p_{.05}$ & $\hat{z}_{.05}$ & $p_{.05}$ & $\hat{z}_{.05}$ \\
\hline$M G$ & 2.36 & 1.93 & 5.43 & 2.17 & 7.05 & 2.12 & 6.94 & 2.14 \\
\hline POLS & 99.79 & 17.45 & 73.39 & 12.04 & 5.05 & 2.02 & 89.17 & 29.74 \\
\hline$F E$ & 99.55 & 10.31 & 71.89 & 9.81 & 5.68 & 2.04 & 85.21 & 21.47 \\
\hline
\end{tabular}


Table 7 Response surfaces (Heterogeneous slopes)

\begin{tabular}{ccccccc}
\hline \multicolumn{1}{c}{ i) $I(0)$ errors } & \multicolumn{9}{c}{ POLS } & \multicolumn{2}{c}{$F E$} \\
\hline & $\bar{\beta}$ & $S S D(\hat{\beta})$ & $\bar{\beta}$ & $S S D(\hat{\beta})$ & $\bar{\beta}$ & $S S D(\hat{\beta})$ \\
\hline$\hat{a}$ & -.0074 & .8320 & .0422 & -2.367 & .0439 & -2.311 \\
& $(-.642)$ & $(21.103)$ & $(3.915)$ & $(-24.432)$ & $(4.138)$ & $(-20.397)$ \\
$\hat{b}$ & $-1.82 \mathrm{E}-4$ & -.4942 & $3.22 \mathrm{E}-4$ & -.4936 & $5.09 \mathrm{E}-5$ & -.4980 \\
& $(-.128)$ & $(-90.521)$ & $(.262)$ & $(-38.470)$ & $(.0417)$ & $(-34.797)$ \\
$\hat{c}$ & $1.83 \mathrm{E}-3$ & -1.008 & $1.53 \mathrm{E}-3$ & $-2.71 \mathrm{E}-2$ & $1.52-3$ & $-8.12 \mathrm{E}-2$ \\
& $(1.183)$ & $(-178.991)$ & $(1.121)$ & $(-2.209)$ & $(1.122)$ & $(-5.670)$ \\
$\bar{R}^{2}$ & .0034 & .9977 & .0052 & .9612 & .0036 & .9540 \\
\hline$i i) I(1)$ errors & & & & & \\
\hline$\hat{a}$ & -.0023 & -.8347 & .0376 & -.7635 & .0394 & -1.0616 \\
& $(-.308)$ & $(-13.926)$ & $(6.258)$ & $(-20.050)$ & $(6.806)$ & $(-22.150)$ \\
$\hat{b}$ & $-7.949 \mathrm{E}-4$ & -.4895 & $1.78 \mathrm{E}-3$ & -.5068 & $1.59 \mathrm{E}-3$ & -.5002 \\
& $(-.554)$ & $(-43.309)$ & $(1.481)$ & $(-65.619)$ & $(1.395)$ & $(-71.776)$ \\
$\hat{c} \hat{c}$ & $1.31 \mathrm{E}-3$ & $-5.49 \mathrm{E}-3$ & $1.01 \mathrm{E}-3$ & $-5.40 \mathrm{E}-3$ & $8.59 \mathrm{E}-4$ & -.0033 \\
& $(1.183)$ & $(-.654)$ & $(1.286)$ & $(-.889)$ & $(1.089)$ & $(-.476)$ \\
$\bar{R}^{2}$ & -.0047 & .9755 & .0353 & .9871 & .0252 & .9847 \\
\hline
\end{tabular}

Notes: $t$-ratios in parentheses. Panel I specifications are used. Functional forms: $\ln (\bar{\beta})=a+b \ln N+c \ln T+v$

$\ln S S D(\hat{\beta})=a+b \ln N+c \ln T+v$ 
Table 8 Dispersion of group estimates $\hat{\beta}_{i}$

\begin{tabular}{|c|c|c|c|c|c|c|}
\hline Panel & $\sigma\left(\hat{\beta}_{i}\right)$ & Min. & Max. & $Z\left(\hat{\beta}_{i}\right)=$ & $\frac{\hat{\beta}_{i}-\bar{\beta}}{\sigma\left(\hat{\beta}_{i}\right)}$ & $>2$ \\
\hline$C P I-D M$ & .3439 & $\begin{array}{c}-.1488 \\
\text { (Austria) }\end{array}$ & $\begin{array}{c}1.1824 \\
\text { (Canada) }\end{array}$ & \multicolumn{3}{|c|}{$\begin{array}{l}-2.6996 \\
\text { (Austria) }\end{array}$} \\
\hline$C P I-U S \$$ & .3582 & $\begin{array}{c}.5999 \\
\text { (Finland) }\end{array}$ & $\begin{array}{c}1.9678 \\
\text { (Japan) }\end{array}$ & \multicolumn{3}{|c|}{$\begin{array}{l}2.4675 \\
\text { (Japan) }\end{array}$} \\
\hline$W P I-D M$ & .3157 & $\begin{array}{c}.1255 \\
\text { (Austria) }\end{array}$ & $\begin{array}{c}1.3721 \\
\text { (Switzerland) }\end{array}$ & \multicolumn{3}{|c|}{$\begin{array}{l}-2.9098 \\
\text { (Austria) }\end{array}$} \\
\hline$W P I-U S \$$ & .2470 & $\begin{array}{c}.5504 \\
\text { (United Kingdom) }\end{array}$ & $\begin{array}{c}1.5137 \\
\text { (Japan) }\end{array}$ & \multicolumn{3}{|c|}{$\begin{array}{c}-2.2558 \\
(\mathrm{UK})\end{array}$} \\
\hline
\end{tabular}


Table 9 Panel estimates of static PPP regressions

\begin{tabular}{lccc}
\hline & $M G$ & $F E$ & $P O L S$ \\
\hline CPI-DM panel & & & \\
$\hat{\beta}($ se $)$ & $0.780(.083)$ & $0.933(.004)$ & $0.968(.004)$ \\
$t$-statistic $(\beta=1)$ & $-2.642^{*}$ & $-18.847^{*}$ & $-7.436^{*}$ \\
CPI-US\$ panel & & & \\
$\hat{\beta}($ se $)$ & $1.084(.087)$ & $0.964(.007)$ & $1.004(.006)$ \\
$t$-statistic $(\beta=1)$ & .965 & $-5.167^{*}$ & 0.702 \\
$W P I-D M$ panel & & & \\
$\hat{\beta}($ se $)$ & $1.044(.088)$ & $1.036(.004)$ & $1.066(.004)$ \\
$t$-statistic $(\beta=1)$ & 1.505 & $8.427^{*}$ & $15.666^{*}$ \\
$W P I$-US\$ & & & \\
$\hat{\beta}($ se $)$ & $1.108(.068)$ & $1.001(.008)$ & $1.069(.006)$ \\
$t$-statistic $(\beta=1)$ & 1.570 & 1.570 & $12.072^{*}$ \\
\hline Notes: ${ }^{*}$ indicates rejection of the long run PPP hypothesis.
\end{tabular}




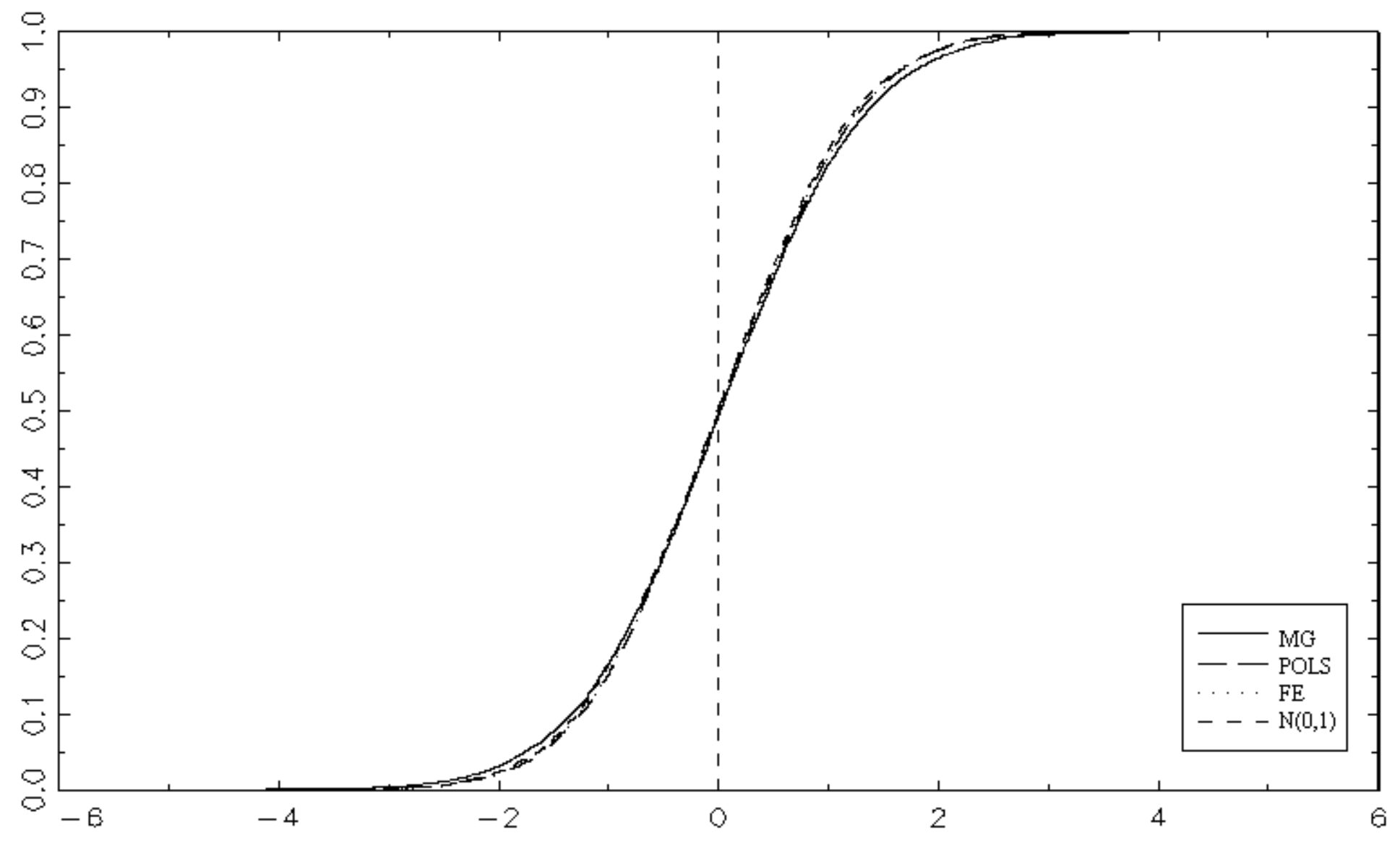

Figure 1(A) EDF of $t$-statistic (PANEL II, Homogeneous slope, I(0) errors) 


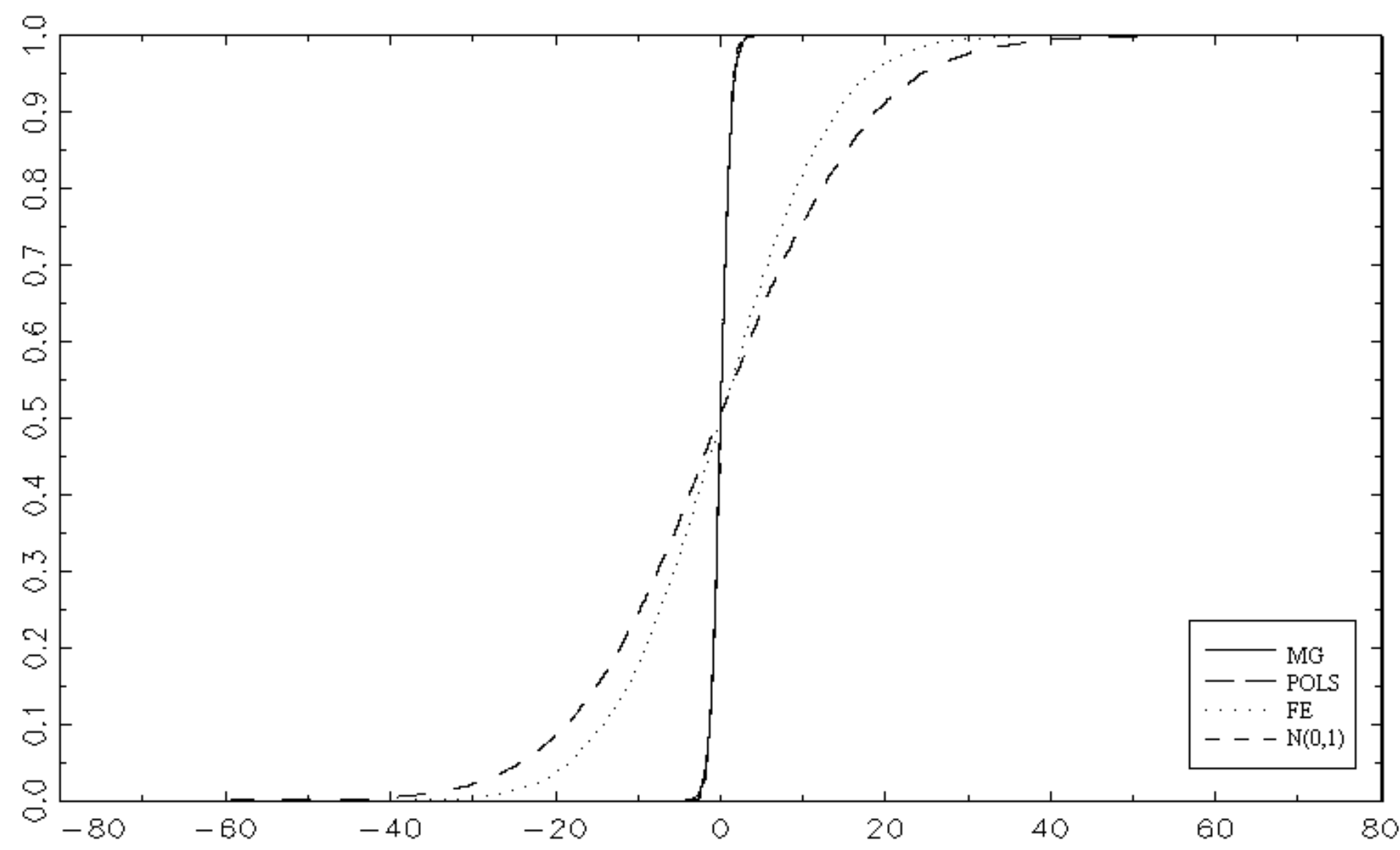

Figure 1(B) EDF of $t$-statistic (PANEL II, Homogeneous slope, I(1) errors) 
i) $I(0)$ errors

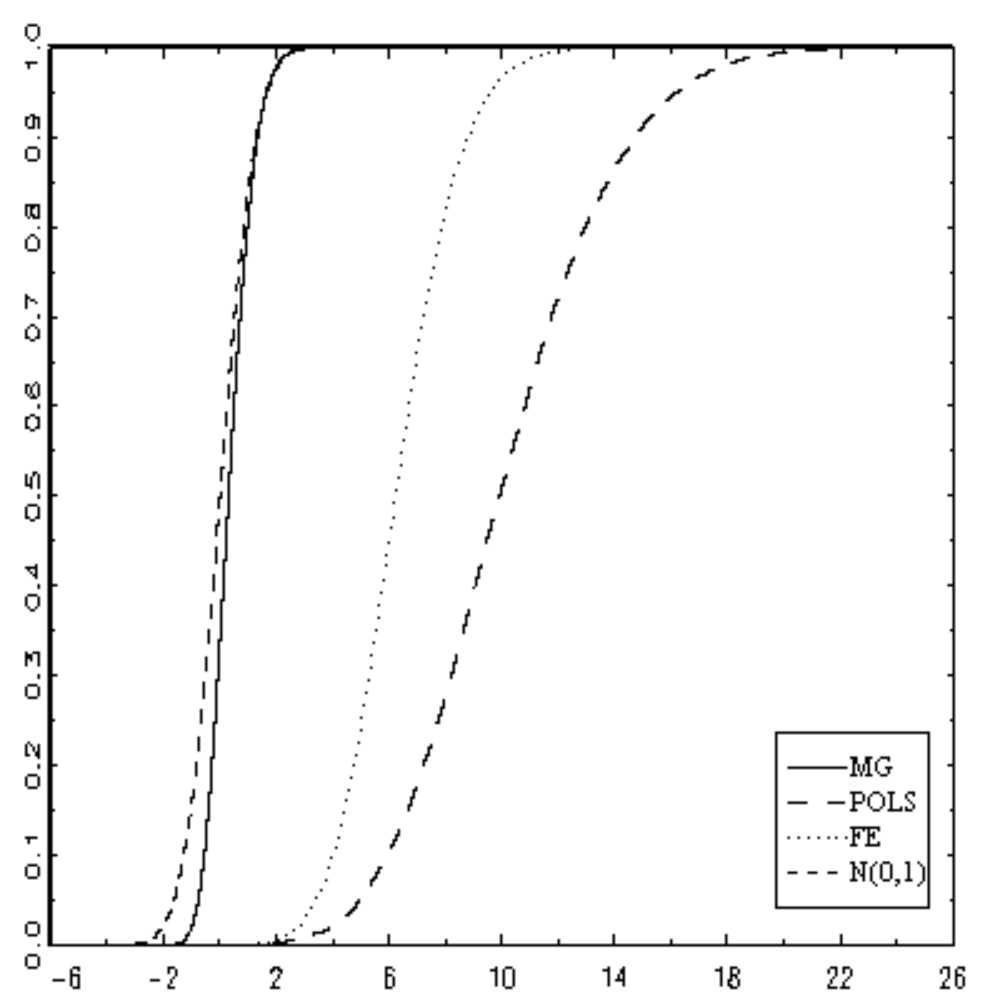

ii) $I(1)$ errors

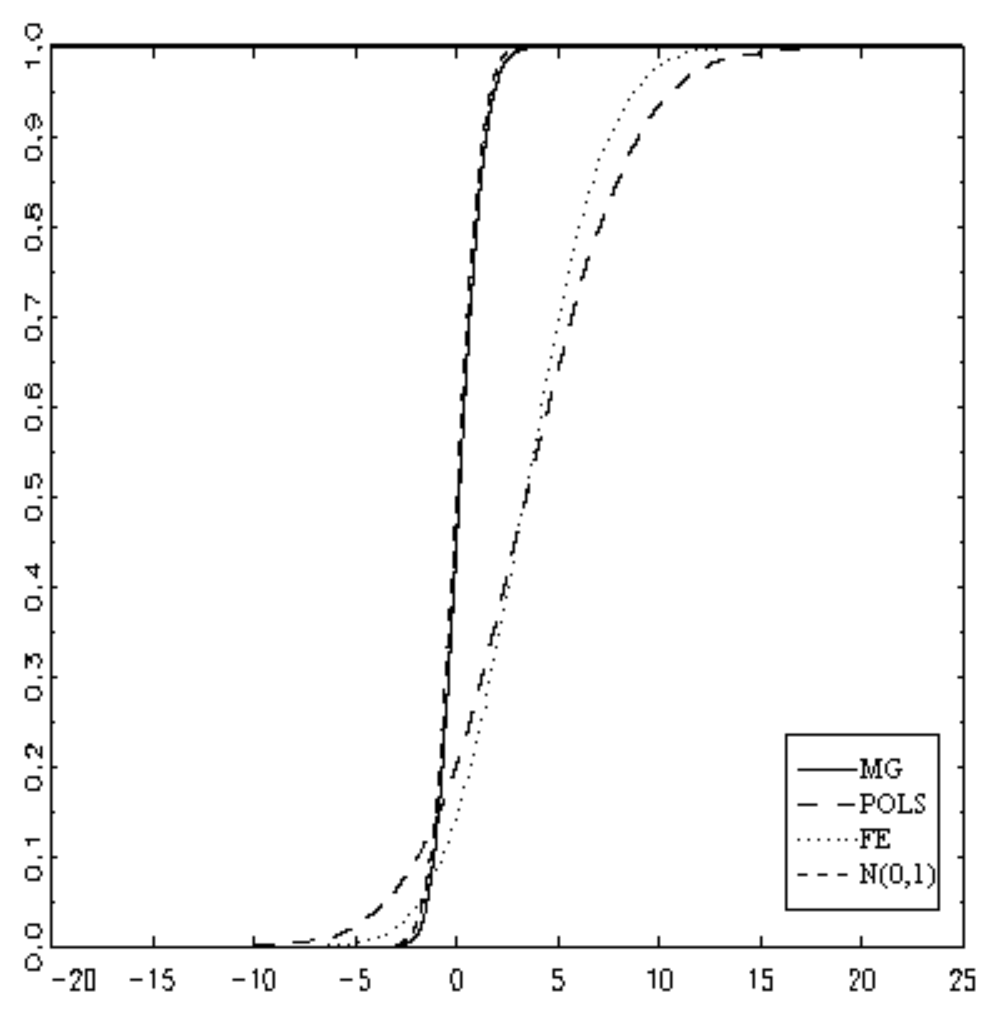

Figure 2(A) EDF of $t$-statistic (PANEL I, Heterogeneous slope) 
i) $\mathrm{I}(0)$ errors

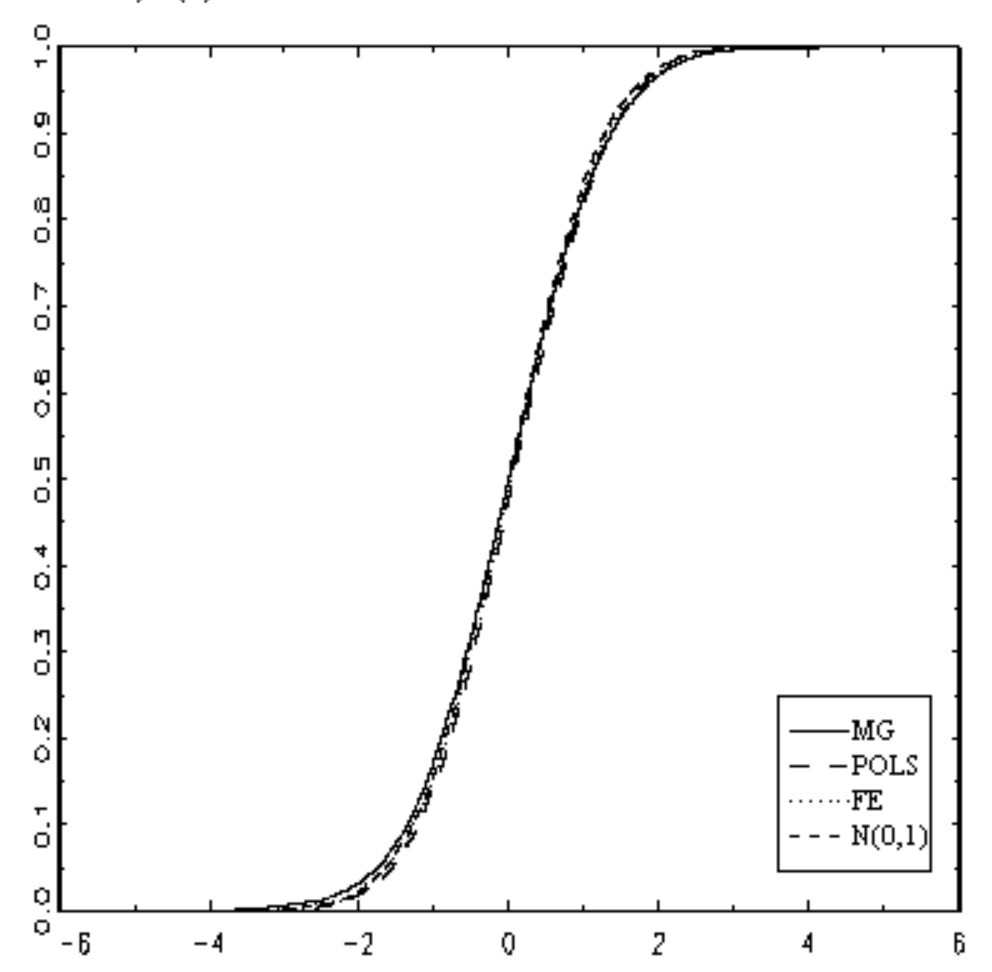

ii) I(1) errors

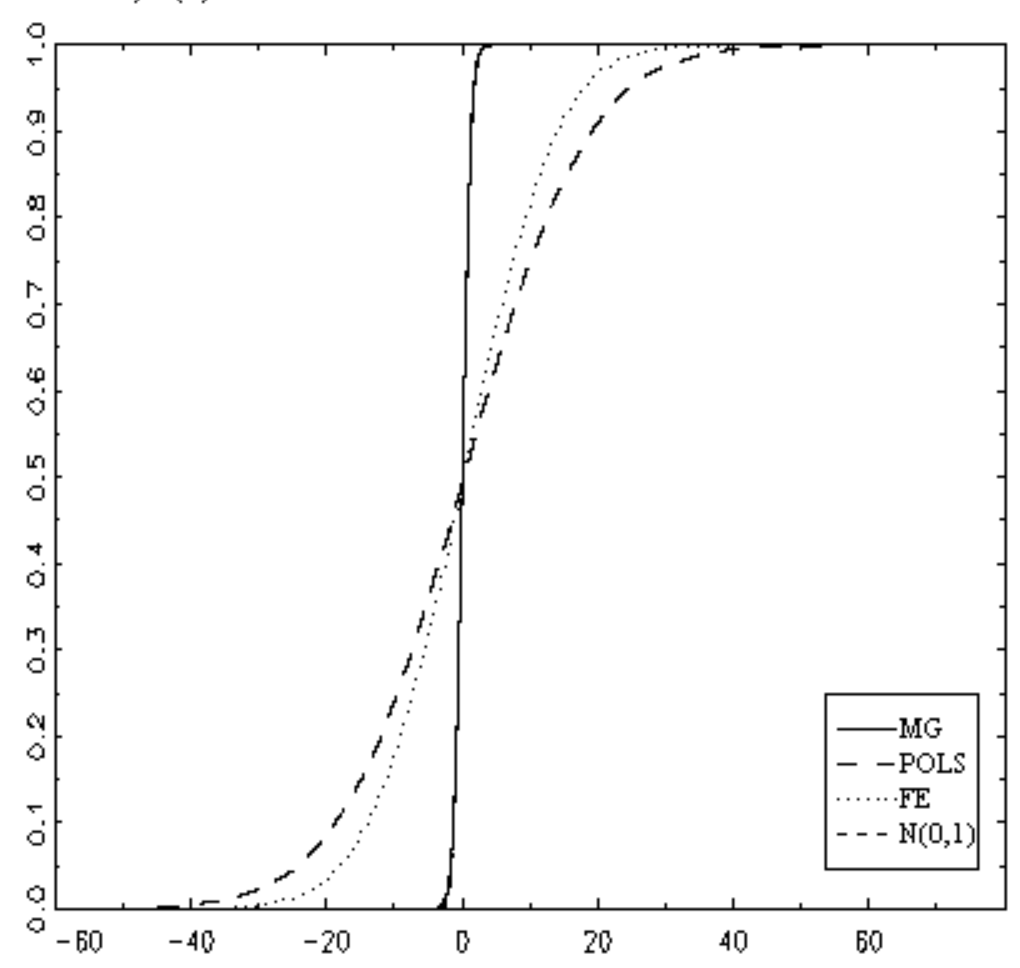

Figure 2(B) EDF of $t$-statistic (PANEL II, Heterogeneous slope) 


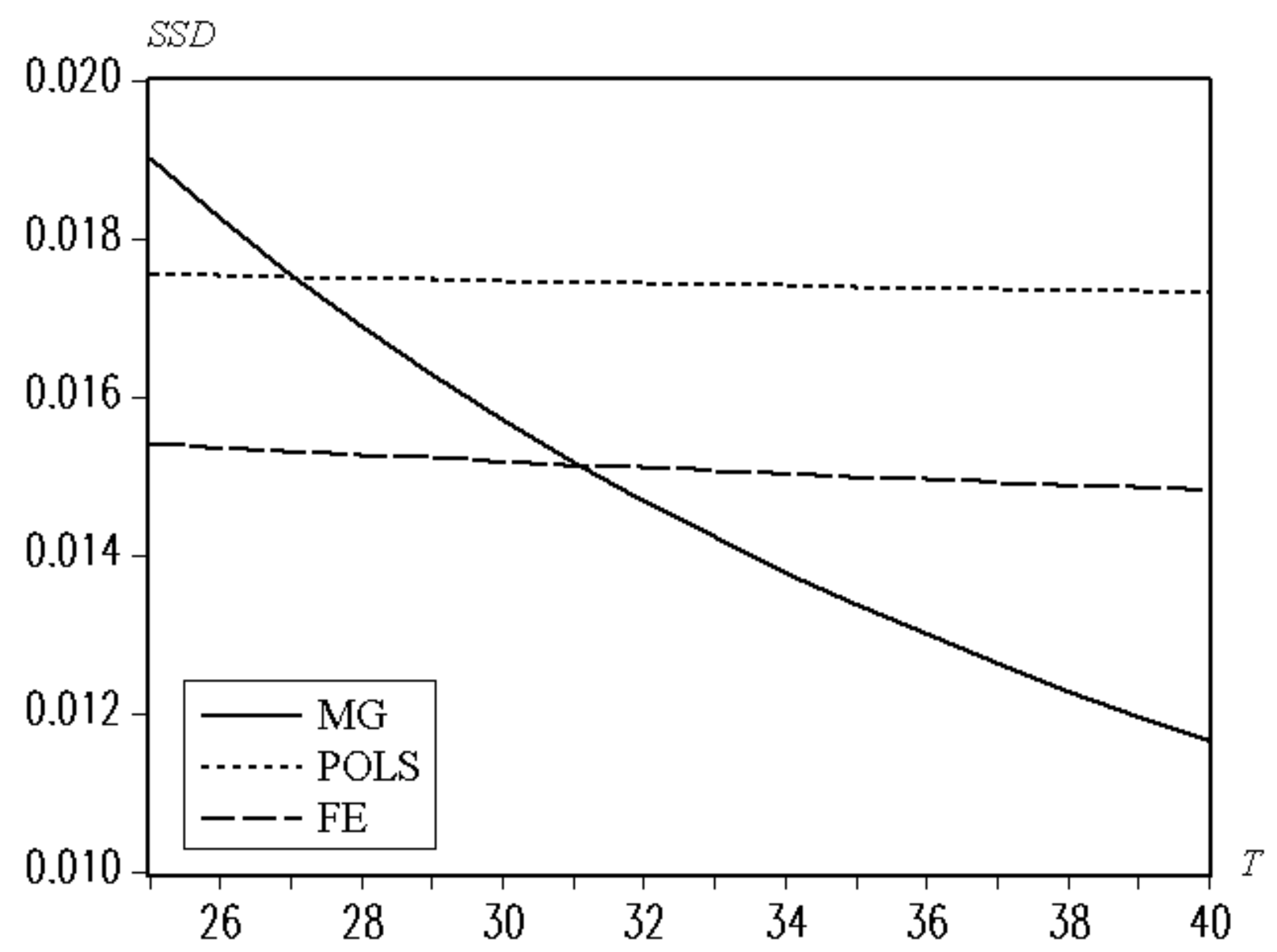

Figure 3 Response surface of $S S D$ of slope coefficient estimate $(N=25)$. Heterogeneous panel. I $(0)$ errors. 


\section{List of other working papers:}

\section{1}

1. Soosung Hwang and Steve Satchell, GARCH Model with Cross-sectional Volatility; GARCHX Models, WP01-16

2. Soosung Hwang and Steve Satchell, Tracking Error: Ex-Ante versus Ex-Post Measures, WP01-15

3. Soosung Hwang and Steve Satchell, The Asset Allocation Decision in a Loss Aversion World, WP01-14

4. Soosung Hwang and Mark Salmon, An Analysis of Performance Measures Using Copulae, WP01-13

5. Soosung Hwang and Mark Salmon, A New Measure of Herding and Empirical Evidence, WP01-12

6. Richard Lewin and Steve Satchell, The Derivation of New Model of Equity Duration, WP0111

7. Massimiliano Marcellino and Mark Salmon, Robust Decision Theory and the Lucas Critique, WP01-10

8. Jerry Coakley, Ana-Maria Fuertes and Maria-Teresa Perez, Numerical Issues in Threshold Autoregressive Modelling of Time Series, WP01-09

9. Jerry Coakley, Ana-Maria Fuertes and Ron Smith, Small Sample Properties of Panel Timeseries Estimators with I(1) Errors, WP01-08

10. Jerry Coakley and Ana-Maria Fuertes, The Felsdtein-Horioka Puzzle is Not as Bad as You Think, WP01-07

11. Jerry Coakley and Ana-Maria Fuertes, Rethinking the Forward Premium Puzzle in a Nonlinear Framework, WP01-06

12. George Christodoulakis, Co-Volatility and Correlation Clustering: A Multivariate Correlated ARCH Framework, WP01-05

13. Frank Critchley, Paul Marriott and Mark Salmon, On Preferred Point Geometry in Statistics, WP01-04

14. Eric Bouyé and Nicolas Gaussel and Mark Salmon, Investigating Dynamic Dependence Using Copulae, WP01-03

15. Eric Bouyé, Multivariate Extremes at Work for Portfolio Risk Measurement, WP01-02

16. Erick Bouyé, Vado Durrleman, Ashkan Nikeghbali, Gael Riboulet and Thierry Roncalli, Copulas: an Open Field for Risk Management, WP01-01

\section{0}

1. Soosung Hwang and Steve Satchell, Valuing Information Using Utility Functions, WP00-06

2. Soosung Hwang, Properties of Cross-sectional Volatility, WP00-05

3. Soosung Hwang and Steve Satchell, Calculating the Miss-specification in Beta from Using a Proxy for the Market Portfolio, WP00-04

4. Laun Middleton and Stephen Satchell, Deriving the APT when the Number of Factors is Unknown, WP00-03

5. George A. Christodoulakis and Steve Satchell, Evolving Systems of Financial Returns: AutoRegressive Conditional Beta, WP00-02

6. Christian S. Pedersen and Stephen Satchell, Evaluating the Performance of Nearest Neighbour Algorithms when Forecasting US Industry Returns, WP00-01

1999

1. Yin-Wong Cheung, Menzie Chinn and Ian Marsh, How do UK-Based Foreign Exchange Dealers Think Their Market Operates?, WP99-21 
2. Soosung Hwang, John Knight and Stephen Satchell, Forecasting Volatility using LINEX Loss Functions, WP99-20

3. Soosung Hwang and Steve Satchell, Improved Testing for the Efficiency of Asset Pricing Theories in Linear Factor Models, WP99-19

4. Soosung Hwang and Stephen Satchell, The Disappearance of Style in the US Equity Market, WP99-18

5. Soosung Hwang and Stephen Satchell, Modelling Emerging Market Risk Premia Using Higher Moments, WP99-17

6. Soosung Hwang and Stephen Satchell, Market Risk and the Concept of Fundamental Volatility: Measuring Volatility Across Asset and Derivative Markets and Testing for the Impact of Derivatives Markets on Financial Markets, WP99-16

7. Soosung Hwang, The Effects of Systematic Sampling and Temporal Aggregation on Discrete Time Long Memory Processes and their Finite Sample Properties, WP99-15

8. Ronald MacDonald and Ian Marsh, Currency Spillovers and Tri-Polarity: a Simultaneous Model of the US Dollar, German Mark and Japanese Yen, WP99-14

9. Robert Hillman, Forecasting Inflation with a Non-linear Output Gap Model, WP99-13

10. Robert Hillman and Mark Salmon , From Market Micro-structure to Macro Fundamentals: is there Predictability in the Dollar-Deutsche Mark Exchange Rate?, WP99-12

11. Renzo Avesani, Giampiero Gallo and Mark Salmon, On the Evolution of Credibility and Flexible Exchange Rate Target Zones, WP99-11

12. Paul Marriott and Mark Salmon, An Introduction to Differential Geometry in Econometrics, WP99-10

13. Mark Dixon, Anthony Ledford and Paul Marriott, Finite Sample Inference for Extreme Value Distributions, WP99-09

14. Ian Marsh and David Power, A Panel-Based Investigation into the Relationship Between Stock Prices and Dividends, WP99-08

15. Ian Marsh, An Analysis of the Performance of European Foreign Exchange Forecasters, WP99-07

16. Frank Critchley, Paul Marriott and Mark Salmon, An Elementary Account of Amari's Expected Geometry, WP99-06

17. Demos Tambakis and Anne-Sophie Van Royen, Bootstrap Predictability of Daily Exchange Rates in ARMA Models, WP99-05

18. Christopher Neely and Paul Weller, Technical Analysis and Central Bank Intervention, WP9904

19. Christopher Neely and Paul Weller, Predictability in International Asset Returns: A Reexamination, WP99-03

20. Christopher Neely and Paul Weller, Intraday Technical Trading in the Foreign Exchange Market, WP99-02

21. Anthony Hall, Soosung Hwang and Stephen Satchell, Using Bayesian Variable Selection Methods to Choose Style Factors in Global Stock Return Models, WP99-01

\section{8}

1. Soosung Hwang and Stephen Satchell, Implied Volatility Forecasting: A Compaison of Different Procedures Including Fractionally Integrated Models with Applications to UK Equity Options, WP98-05

2. Roy Batchelor and David Peel, Rationality Testing under Asymmetric Loss, WP98-04

3. Roy Batchelor, Forecasting T-Bill Yields: Accuracy versus Profitability, WP98-03

4. Adam Kurpiel and Thierry Roncalli, Option Hedging with Stochastic Volatility, WP98-02

5. Adam Kurpiel and Thierry Roncalli, Hopscotch Methods for Two State Financial Models, WP98-01 